\title{
“Peart” Human Factors Model for Aviation Maintenance
}

\author{
Kejiao YANG ${ }^{1, a}$, Yonghua $\mathrm{FAN}^{2, \mathrm{~b}}$ \\ ${ }^{1}$ Kunming Airlines,Safety Supervision Department,Kunming 650000,China \\ ${ }^{2}$ Shenzhen Airlines, Maintenance Engineering Department, Guangzhou 510000, China. \\ a 28439892@qq.com, b B00032@shenzhenair.com
}

Keywords: Human Factors, aviation maintenance, model.

\begin{abstract}
Nowadays Human Factors in aviation maintenance has become a important cause of aviation accidents. So there are a lot of Human Factors models for aviation maintenance. The "pear" model is one of the most famous Human Factors models. In this paper, the "pear" Human Factors analysis model was systematically introduced. After then an improved "pear" Human Factors analysis model for aviation maintenance is proposed, named "peart" Human Factors analysis model, which is based on the authors" work experience. Both the "pear" model and the "peart" model are discussed in detail.
\end{abstract}

\section{Introduction}

Safety is the most important things to airlines. Although the aviation accident ratio is decreased with the aircraft design and manufacture technology development, the aviation accident still happens. In the Boeing Company's report ${ }^{[1]}$, from 1959 to 2002, there were 1,421 aviation accidents (including ground test accidents), and that number had decreased to 407 from 2003 to 2012. There was a significantly decline in aviation accident number, but the number itself is still too large, almost 4 accidents per year. So, measures must be taken to further decrease the aviation accidents. Fist of all, the reason of aviation accidents has to be investigated.

The aircraft manufacturing industry has a rapid development in 21 century, the aviation accidents caused by design and manufacture faults has decreased significantly. The aviation accidents are mainly caused by Human Factors nowadays. According to the statistics of international air transport association (IATA), about $80 \%$ aviation accidents were caused by human unsafe acts ${ }^{[2]}$. The aviation maintenance is one of the most important links in aviation safety, the human errors in aviation maintenance is also an important cause of aviation accidents ${ }^{[3]}$. So there are so many Human Factors model for aviation maintenance proposed, such as the "shell" model ${ }^{[4,5]}$, the "reason" model ${ }^{[6,7]}$ and the "pear" model ${ }^{[8,9]}$. The "shell" model is based on the ergonomics; the "reason" model is focused on the importance of organization; the "pear" model is similar with the "shell" model, but is more easily to be understood than "shell" model. In this paper, the "pear' model was introduced, both its merits and demerits had been discussed. After then, a improved "pear" model named "peart" model was presented.

\section{The "pear" model}

The "pear" model is proposed by William B. Johnson and Michael E. Maddox ${ }^{[8]}$. The "pear" model is easily to be understood, so it is very popular in aviation Human Factors analysis, especially in aviation maintenance. The letter "P" stands for "people", who works in aviation maintenance. The letter " $\mathrm{e}$ " means "environment", which includes both the physical environment and the organization environment. The letter "a" is short for "actions", which should be done in aviation maintenance. The letter "r" signifies "resource", which is needed in maintenance. The components of the "pear" model are shown in Fig.1. 


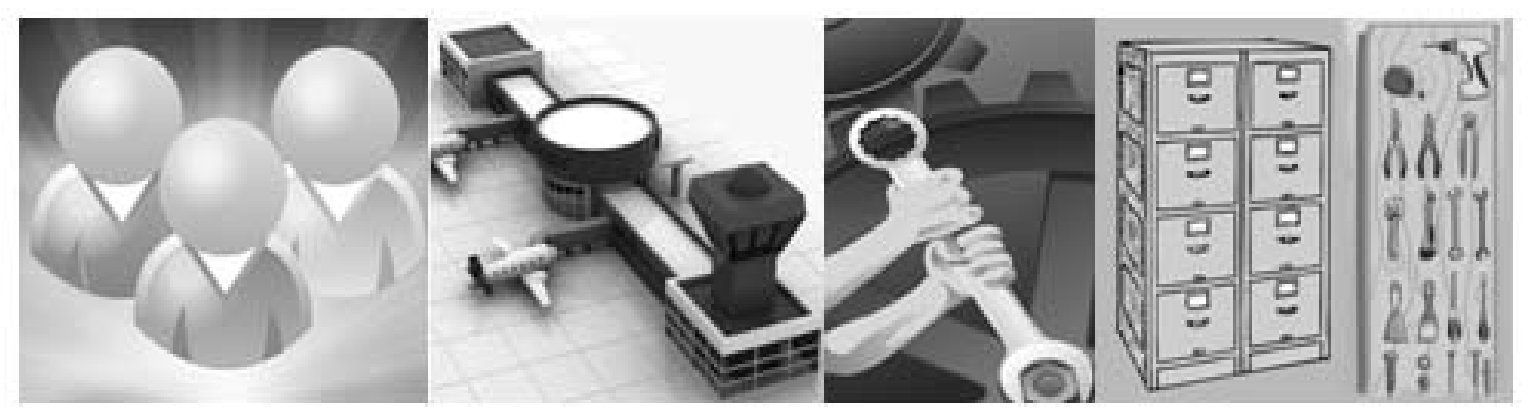

\section{people environment action resource}

Fig.1 The components of "pear" model

"People" is the most important part of "pear" model, because the maintenance work is accomplished by the people. The "people" element includes the human physiology, the human psychology and the human social psychology factors. The "environment" part include two main subjects, physical environment and the organization environment. The work place condition belongs to physical environment. The management and corporation culture is the part of organization environment. The "action" is the final execution part of aviation maintenance, which directly affecting the aviation maintenance safety. The "resource" element in the model includes all the resource that needed in aviation maintenance, such as maintenance manuals, job cards, tools, computers, training materials, products supplier and etc. The "people" part, the "environment" part and the "action" part all need the support of "resource" part.

Actually, the "pear" model is similar to the "shell" model ${ }^{[4]}$. As shown in Fig.2, in the "shell" model, the letter "s" means "software", including all the non physical resources such as procedures, manuals and job cards. The letter " $h$ " means the "hardware", including all the physical resources such as aircraft, tools, and equipments. The letter "e" means the "environment", containing both the natural environment and the social environment. The central letter "l" means "livewire", which equals to the man who does the work. The last letter "l" also means "livewire", but it stands for teamwork, leadership, communication and etc. the center " 1 " is the most important parts of the "shell" model, which connects with the "s", the " $h$ ", the "e" and the other "l" through a particular relationship. The "people" part in the "pear" model equals to the two "livewire" parts in the "shell" model. The "environment" and the "resource" in the "pear" model equal to the "environment", the "software" and the "hardware" in the "shell" model. The "action" in the "pear" model equals to the relationship between the central "livewire" and the other parts in the "shell" model. So, the "pear" model is similar to the "shell" model. Because the parts partition in the "pear" model is clearer than that in the "shell" model, the "pear" model becomes more and more popular.

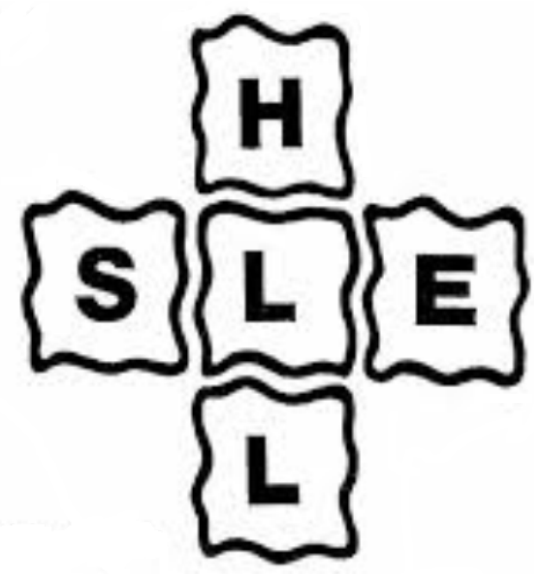

Fig.2 The "shell" model 


\section{The limitation of the "pear" model}

The "pear" model includes almost all the elements that will influence the aviation maintenance safety. The word "pear" is a kind of fruit that is easy to remember for aviation maintenance worker. So the "pear" model is easy to be understood and be remembered. In recent years, the "pear" model has become a popular Human Factors analysis model in aviation maintenance. Although the "pear" model includes almost all the elements that will influence the aviation maintenance safety, there is still an important factor in aviation maintenance Human Factors analysis not described clearly, that factor is "time".

Based on our work experience, the "time" is an important factor that will affect the aviation maintenance and the maintenance worker. For an example, the feeling of working in daytime is quite different from that in the night. Perhaps, the different work feelings between working in daytime and in the night may belong to the human psychology that described in the "pear" model. But, firstly, the "time" element is not clearly described in the "pear" model; secondly, time does not only mean the daytime and night time, but also mean the date, the season, the year and even the era. The "time" does not affect the aviation maintenance worker, but also affects the aviation maintenance in many ways. For instance, how the aviation maintenance is, in the air transportation busy-season and in the air transport off-season are very different. In the air transportation busy- season, the number of flights may become 10 times of that in off-season, even 100 times in some times. The rapid increase of flights not only increase the aviation maintenance worker's psychological pressure, but also increases the support pressure in the aviation maintenance "environment", "action" and "resource". In busy-season, all of the resources are always lacking, all of the airline's staffs are busy, so the organization environment is lack of assurance, and all of the maintenance workers' actions may be lack of strength and precision. So, it is clearly that, "time" obviously affects all the part of the "pear" Human Factors analysis.

So a new Human Factors analysis model used for aviation maintenance was proposed named the "peart" model, based on the "pear" model, considering the time element.

\section{The "peart" model}

The "peart" model is also a simple and easily understood Human Factors analysis model. The "peart" model is based on the "pear" model, The concept of the "peart" model is shown in Fig.3.

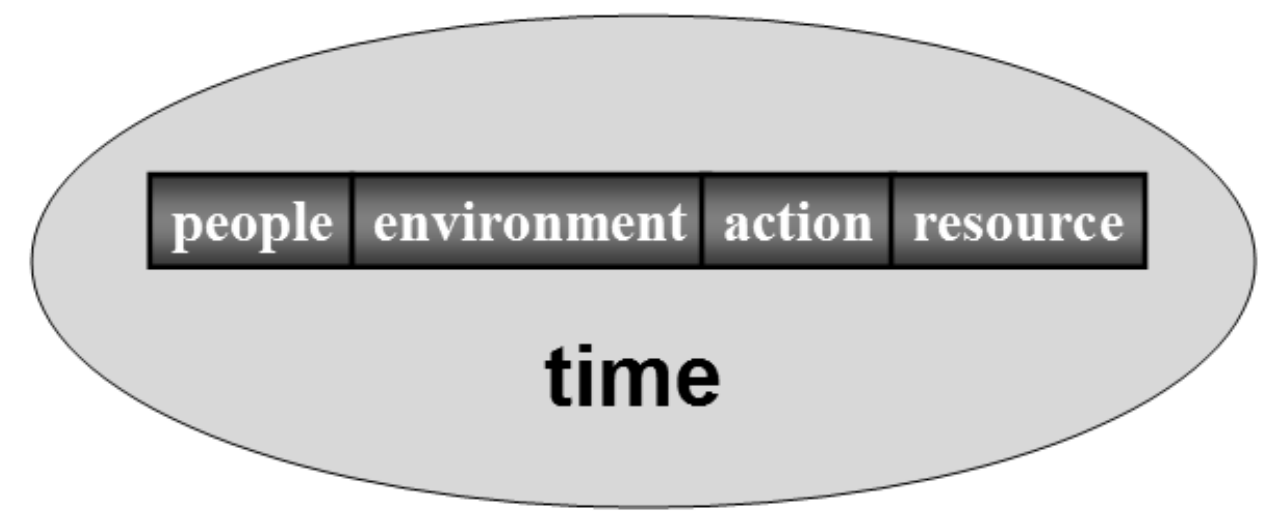

Fig. 3 The concept of the "peart" model

The model name "peart" is come from the model "pear", by adding the letter " $t$ " to the word "pear". But, as shown in Fig.3, the concept of the "peart" model is not just add the "time" element to the "pear" model's tail part. The "time" element in the "peart" model is the leader element. All other four elements are affected by "time". The core idea of the "peart" model is that, when discussing the Human Factors, all the other parts are in a specific time, and different time means different features. When anglicizing the aviation maintenance Human Factors, the "time" should be considered in the 
first place. Is now the air transportation busy-season or off-season? When it is the busy-season, in the "people" part, the "environment" part, the "action" part and the "resource" part, what things should be focused on? Only if the "time" element has been taken into account, the Human Factors analysis will be more realistic and accurate. The "people" part, the "environment" part, the "action" part and the "resource" part in the "peart' model are the same as in the "pear" model. So, the "peart" model is mainly come form the "pear" model.

The "pear" Human Factors analysis model can be remembered as the pear, a kind of fruit, so it is easy to remembered and accepted. When adding the "time" element to the "pear" model, the new model name becomes "peart". The word "peart" means "lively" and "cheerful", it is also easy to be remembered. In addition, using the word "peart" as the new model's name is very vividly: when add the "time" element to the "pear" model, the model becomes lively and cheerful, the importance of the "time" part is obviously. So the "peart" model is also a easy

\section{Summary}

The "peart" model is based on the famous "pear" model. The "time" element has a great impact on the aviation maintenance Human Factors analysis. By adding the "time" element to the "pear" model, the "peart" modle makes the Human Factors analysis more realistic and accurate. The "peart" model is easy to be understood and easy to be remembered. Using the "peart" model in the daily aviation maintenance Human Factors analysis, the human errors may be decreased further more.

\section{References}

[1] Boeing Company. statistical summary of commercial jet airplane accidents worldwide operation 1959-2012[R], Commercial Airplanes. 2013: 1-14

[2] Xiaomin Bu. Research on Human Factor analysis of aviation accidents/incidents[D]. Civil Aviation University of China, 2008:1-3 (in Chinese)

[3] China Civil Aviation Safety Office. China civil aviation safety report(2005)[R]. Peking, 2006:29 (in Chinese)

[4] Hawkins F H. Human factors in flight[M]. Aldershot: Ash gate, 1987

[5] Tao Sun. Discussions on Human Factors in aviation maintenance [J]. Science and Technology Innovation Herald, 2011, 31:231(in Chinese)

[6] Reason J. Human eror[M]. New York: Cambridge University Press, 1990

[7] Yao Tong, Weihua Chen. Researches on the analysis of Human Factors in aviation maintenance and preventive measures[J]. Science and Technology Vision, 2013, 19:51(in Chinese)

[8] Yang Liu, Yonggang Wang. A model to explain Human Factors in aviation maintenance-the introduction to pear model[J]. Aviation Maintenance \& Engineering, 2010, 5:81-82(in Chinese)

[9] Information on http://www.skybrary.aero/index.php/PEAR_Model 